\title{
Centro-monumento e a patrimonialização de Sobral, Ceará, Brasil ${ }^{\mathrm{i}}$
}

\author{
Nilson Almino de Freitas ${ }^{1}$
}

Resumo: O artigo discute o processo de patrimonialização da cidade de Sobral, no estado brasileiro do Ceará, como pautada em uma determinada forma de ver a urbanização e a educação. A política de preservação do patrimônio cultural aplicada no sítio histórico é usada como lugar de um discurso que define um modelo de tradição, ao mesmo tempo de modernidade, construídos pelo quase-grupo político ancorado nos "Ferreira Gomes”. Este discurso está presente nas políticas públicas de urbanização e educação. O artigo faz a leitura do PDDU da cidade, e de livro didático de história e geografia local produzido para o ensino fundamental municipal e tenta explicitar como a patrimonialização está presente nestes documentos, cruzando com outras fontes documentais e lembranças do pesquisador. Esta leitura mostra que a identidade e o patrimônio cultural tombado, portanto, não podem ser entendidos como representativos de todos os sobralenses, mas daqueles que defendem um determinado modelo de cidade.

Palavras-chave: patrimônio histórico e cultural; centro-monumento; monumentalização; identidade; política.

\section{Centro-monumento y patrimonialización de Sobral, Ceará, Brasil}

Resumen: El artículo analiza el proceso de patrimonialización de la ciudad de Sobral, en el estado brasileño de Ceará, según una determinada forma de ver la urbanización y la educación. La política de preservación del patrimonio cultural aplicada en el sitio histórico se utiliza como lugar para un discurso que define un modelo de tradición, al mismo tiempo de la modernidad, construido por el grupo cuasi político anclado en la familia "Ferreira Gomes". Este discurso está presente en las políticas públicas de urbanización y educación. El artículo lee el PDDU de la ciudad, y un libro de texto sobre historia local y geografía producido para la educación primaria municipal e intenta explicar cómo el patrimonio está presente en estos documentos, cruzando con otras fuentes documentales y recuerdos del investigador. Esta lectura muestra que la identidad y el patrimonio cultural enumerados, por lo tanto, no pueden entenderse como representativos de todos los Sobralenses, sino de aquellos que defienden un determinado modelo de ciudad.

Palabras clave: patrimonio histórico y cultural; centro de monumento; monumentalización; identidad; política.

\section{The "monument center" and patrimonialization of Sobral, Ceará, Brazil}

\begin{abstract}
The article discusses the process of patrimonialization of the city of Sobral, in the Brazilian state of Ceará, as guided by a certain way of seeing urbanization and education. The policy of preserving cultural heritage applied at the historic site is used as the place for a discourse that defines a model of tradition, at the same time of modernity, built by the almost political group anchored in the family "Ferreira Gomes". This discourse is present in public policies for urbanization and education. The article reads the PDDU of the city, and a textbook on local history and geography produced for municipal elementary education and tries to explain how heritage is present in these documents, crossing with other documentary sources and memories of the researcher. This reading shows that the identity and cultural heritage listed, therefore, cannot be understood as representative of all Sobralenses, but of those who defend a certain model of city.
\end{abstract}

Keywords: historical and cultural heritage; monument center; monumentalization; identity; politics.

DOI: https://doi.org/10.26512/patryter.v4i7.29311

Como citar este artigo: Freitas, N. A. (2021). Centro-monumento e a patrimonialização de Sobral, Ceará, Brasil. PatryTer - Revista Latinoamericana e Caribenha de Geografia e Humanidades, 4 (7), 120-136. DOI: https://doi.org/10.26512/patryter.v4i7.29311

Recebido: 24 de janeiro de 2020. Aceite: 01 de setembro de 2020. Publicado: 01 de março de 2021.

1 Professor de Antropologia da Universidade Estadual Vale do Acaraú - UVA/Sobral-CE. ORCID: https://orcid.org/0000-0003-0324-3131.E-mail: nilsonalmino@hotmail.com. 


\section{Introdução}

Este artigo é resultado de algumas experiências de pesquisa na cidade de Sobralii, no estado brasileiro do Ceará, promovidas pelo seu autor. As questões aqui discutidas são relacionadas a algumas implicações culturais e políticas da preservação do patrimônio histórico no centro da cidade, especialmente aquelas relacionadas a construção social da identidade coletiva na política pública de urbanização e educação. As fontes primárias foram, principalmente, um instrumento jurídico de ordenação urbana e outro de educação, quais sejam: o Plano Diretor de Desenvolvimento Urbano - PDDU, especialmente os relatórios técnicos que o antecedem e o livro didático produzido pela Prefeitura de Sobral para o Ensino Fundamental, "Descobrindo e construindo Sobral: conhecimentos de Geografia e História" (Caracristi \& Saboya, 2002). Estas são as fontes principais neste artigo que serão cruzadas com outras fontes adicionais iii. A figura 1 mostra a localização geográfica de Sobral e área de proteção do sítio histórico.

Esta cidade teve uma parte do núcleo urbano tombado em 2000, como patrimônio histórico nacional, pelo Instituto do Patrimônio Histórico Artístico Nacional - IPHAN. O proponente deste artigo acompanhou este processo, não só como morador da cidade, mas também com interesses em pesquisar sobre o tema. Percebia o investimento do poder público em alinhar a política pública de preservação do patrimônio histórico às tradições que remetem a uma suposta estabilidade e continuidade de uma memória coletiva que falava da "sobralidade triunfante" iv . O processo de instrução encaminhado ao IPHAN, que foi usado como instrumento para fundamentar a solicitação, fala de uma história de prosperidade e distinção social (Barbosa, Lucas, Souza \& Vasconcelos, 2000). O que pesou mais para fundamentar o pedido no processo de instrução foi a história da urbanização peculiar, que seria típica do sertão nordestino, tendo a economia da pecuária extensiva como "mito de origem", gerando a riqueza e suposta prosperidade na região.

Neste artigo, quando se usa o conceito de "mito de origem", pensa-se como Balandier (1997), que o entende, não no sentido de uma narrativa ilusória que visa enganar as pessoas.

Figura 1 - Localização geográfica de Sobral, área de proteção rígida, entorno do sítio histórico e bairro centro.

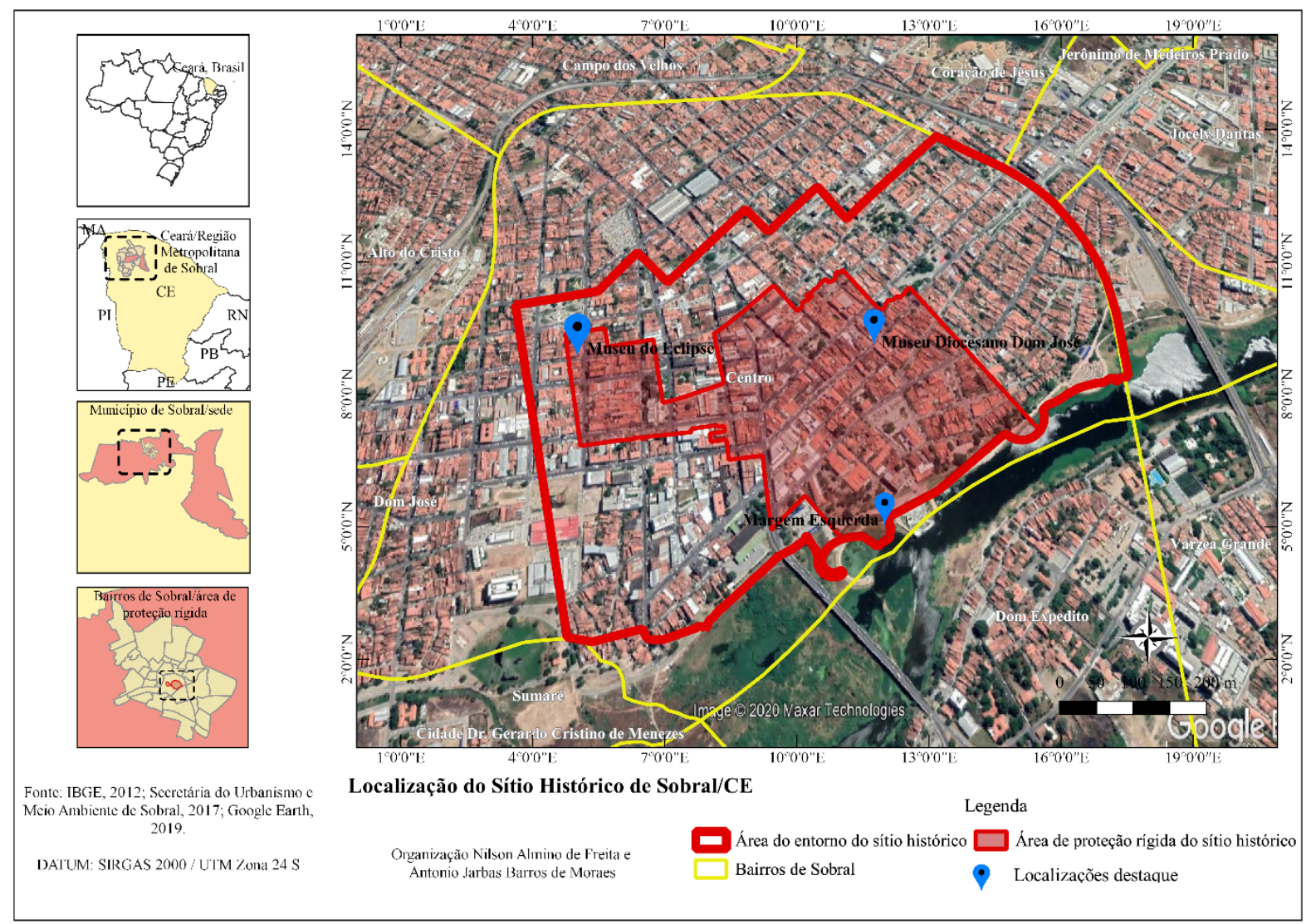

Fonte: IBGE, 2012; Secretaria do Urbanismo e Meio Ambiente de Sobral, 2017; Google Earth, 20 
O mito visa dar sentido, justificar moralmente uma visão do que é considerado próprio da história. Ele organiza e justifica um modelo de se contar a história como quase "natural" do lugar. Este tipo de narrativa apresenta-se em oposição ao princípio da dúvida, básico na metodologia científica. $\mathrm{O}$ questionamento da versão contada tem pouco espaço de contestação na narrativa mitológica. A narrativa que remete a uma história factual estável e linear, apresenta respostas, fugindo da interrogação culta e da possibilidade de outras versões. Os documentos selecionados como fontes para este artigo, apresentam repercussões desta narrativa mítica, o que justifica a escolha para análise, situando-os no seu contexto político e histórico.

O processo de instrução conta uma história organizada por ciclos econômicos, destacando um agente econômico principal e desconsiderando os demais. O mito de origem baseado nas relações econômicas inerentes a pecuária precede a economia do algodão e da industrialização na história linear contada pelo documento. Esta narrativa, que fundamenta uma história de riqueza e prosperidade para a cidade, desde seu mito de origem, aparece com força no discurso vitorioso nas eleições municipais de 1996. A gestão anterior, do prefeito Ricardo Barreto PDS - foi cassada em 1994. Ao ser retirado da gestão, assumia o vice, Aldenor Façanha Júnior PFL -, que rompera com o gestor eleito. Foi testemunhado pelo autor deste artigo, que, quando o vice assumia, desautorizava processos e políticas públicas que o titular tentou implementar. Em recursos, o titular voltava e tinha a mesma atitude de negação da agenda do vice-prefeito. A cidade era marcada por intenso barulho, provocado por fogos de artifício, quando um dos gestores assumia e o outro era retirado do poder. A época ficou conhecida como período do "troca-troca" de prefeitos, provocando sérios problemas na administração pública e na gestão da cidade.

Contrapondo-se a um sentimento de caos administrativo, nas eleições de 1996, o discurso do candidato Cid Ferreira Gomes - ainda no PSDB, na época - era de modernização, retomada do crescimento, organização da gestão, para acabar com este "caos". Associava-se a uma antítese do "atraso". Este "atraso", por sua vez, era apresentado como relacionado às famílias tradicionais que detinham o poder municipal, apesar do grupo de parentes do candidato Cid Gomes pertencer a uma linhagem de políticos que eram aliados a uma destas famílias há poucos anos antes $^{v}$. Mesmo assim, o candidato do PSDB sai vitorioso com o discurso de que era "moderno", diferente da "política tradicional", dentre outras características que tentavam marcar uma diferença radical em comparação com o período do "trocatroca", e com seus opositoresvi.

A nomeação dos grupos políticos relacionados a nomes de família é corrente até hoje na região, não é uma manifestação exclusiva de Sobral. Palmeira e Heredia (1995) percebe isso em várias regiões do Brasil. Os partidos dos candidatos quase não são lembrados no "tempo da política", como informa o autor, a não ser quando se via a sigla do partido político em alguns exemplares do material de divulgação da campanha. O próprio discurso em palanque sempre relacionava os candidatos a nomes de famílias. A disputa em 1996, portanto, era entre os Ferreira Gomes, contra os Prados e Barretos vii. Estes últimos eram acusados por estarem criando um mecanismo de alternância no poder que, no discurso vitorioso, precisava ser rompido. Cid Gomes, relacionado ao "partido" dos Ferreira Gomes, anunciava que representava o moderno, enquanto os demais eram acusados de atrasados e relacionados à "política tradicional" viii.

Paralelo à campanha eleitoral, também em 1996, um casarão que, contemporaneamente, abriga espaço cultural, mais tarde batizado de Casa de Cultura de Sobralix, ia ser derrubado. Um grupo de artistas locais se mobilizou e fez abaixoassinado, encampado também por pessoas que seriam, após vitória eleitoral de 1996, membros da gestão de Cid Gomes. Na época da campanha eleitoral, a discussão da preservação do patrimônio histórico acabou entrando na pauta em função deste episódio. Em 1997, ao assumir a gestão, o então prefeito solicita ao IPHAN o estudo que geraria o Processo de Instrução, base para solicitação do tombamento ${ }^{x}$, aprovado no final de 1999 e registrado no livro de tombo no início de 2000.

O que interessa nesta história para este artigo é que, como já dito, o discurso de campanha de Cid Gomes estava muito amparado na identificação de um candidato que representa o que é "moderno", o que, somente na aparência, não parece ser coerente quando se relaciona a uma proposta de preservação da tradição sobralense. No cotidiano, é comum se pensar a tradição como algo relacionado a um passado que está se perdendo. A narrativa histórica que fundamenta $o$ tombamento de parte do espaço urbano, só falava de vitórias, triunfos e riquezas. A impressão que dá o discurso oficial da gestão municipal iniciada em 1997, incorporado nas demais gestões até 2019, é que Sobral precisa se "modernizar" porque sempre foi moderna. A narrativa, oficializada nos documentos que falam do tombamento e preservação da cidade como patrimônio histórico 
nacional, afirma um ufanismo, sobretudo, um triunfalismo, sem comparação com as demais cidades cearenses ${ }^{x i}$.

Esta mesma narrativa triunfalista está acompanhada de algumas narrativas adicionais que agregam valor a esta que fala da diferença. A própria brincadeira, muito comum na capital cearense, e também difundida entre alguns habitantes de Sobral, de chamá-la de United States of Sobral, parece confirmar esta necessidade de dizer que é diferente e especial. Este estrangeirismo aparece, mesmo que o mito de origem da história oficial fale de algo peculiar ao sertão nordestino, que é a ocupação do interior do estado via pecuária extensiva. Mas, também fala da comprovação empírica da teoria de relatividade de Einstein, em experiência realizada na cidade - que vai ser melhor detalhada em outro momento neste artigo - e fala do estilo europeu, adotado pela elite em diferentes momentos da história, sem precisar o significado deste adjetivo. A narrativa oficial lembra a arquitetura que também caracteriza uma concepção possível de ser entendida, por concepções imprecisas, como algum tipo de europeização. Claro que o termo "europeu" é genérico e abstrato, já que não é possível se pensar uma unidade cultural da Europa que possa ser parâmetro de comparação. Mas, tenta reforçar algo relacionado ao "moderno", civilizado e bom, o que ganhou muita adesão dos eleitores dos "Ferreira Gomes".

Todos estes aspectos são tratados com mais detalhes pelo articulista em vários trabalhos já publicados sobre o tema. Mas, o que se quer ressaltar aqui são algumas implicações relacionados a construção da identidade cultural, nas políticas de urbanização e de educação patrimonial, a partir de duas fontes documentais específicas já mencionadas. Entende-se aqui que, este tipo de política de preservação do patrimônio histórico, seja em cidade do sertão nordestino, seja em qualquer lugar, deve ser entendida como resultante de uma engenharia social promovida pelos agentes sociais que controlam o Estado, contida no contexto de uma batalha de memórias que mostram, muito mais relações de força e conflito, do que harmonia, estabilidade e continuidade linear da história.

Esta tentativa de dar força a narrativa oficial da unidade cultural, pode ser mais evidenciado em alguns documentos que servem para o ordenamento urbano da cidade e outros relacionados a educação, dentre eles os já citados aqui como fonte. A identificação do lugar como tradicional é resultado de relações de força e poder que envolvem o Estado, sustentado na técnica, na política e na moral, na composição do território.
Entretanto, o Estado não pode deixar transparecer que o exercício da força e do poder é o que prevalece nesta empreitada pela preservação de uma tradição. Por isso, o investimento na criação da unidade cultural não deve se restringir ao simples tombamento e reconhecimento nacional como patrimônio histórico. Outras políticas públicas devem estar relacionadas a este investimento. O período entre 1997 e 2019, portanto, parece ser importante marco temporal para entender como isso aconteceu em Sobral.

\section{O Centro-monumento}

O centro da cidade de Sobral, quando ganha o título de Patrimônio Histórico Nacional pelo IPHAN no ano 2000, transforma-se, na narrativa da tecnocracia estatal, em um monumento exemplar atestado pela história que é relacionado a "sobralidade". O território, definido como sendo de proteção rígida, passa a ser propagado por diferentes canais, como testemunho de um passado perpetuado oficialmente pelo tombamento. O destaque é a criação de um "sobralense" e de uma "sobralidade triunfante", representada por histórias conectadas com edificações e manifestações culturais, tornadas "monumento". Os lugares, edificações e práticas são usados e cultuados em honra de uma lembrança de um jeito especial, notável, digno de passar à posteridade. $\mathrm{O}$ centro urbano da sede do município passa a ser o monumento desta lembrança.

Baseando-se nas reflexões de Le Goff (1994), e adaptando ao caso aqui exposto, o centro passou por um processo de confluência entre monumento e documento. $\mathrm{O}$ documento, para o autor francês, é o resultado de uma edição e montagem da história da sociedade que o produziu baseado em um saber competente, de especialistas, para produzi-lo. O documento articula continuidades de uma versão do tempo e do espaço geográfico manipulados pelas lembranças e pelos esquecimentos. $\mathrm{O}$ autor francês mostra que, na metade do século XIX, era comum o conceito de o documento ser sustentado, em alguns marcos epistemológicos positivistas, entendendo-o como um testemunho e também um ensinamento que tem a pretensão de transparecer objetividade e neutralidade, mostrando fatos. Porém, o autor defende que, ao contrário do que transparece esta versão positivista, o documento não é nada mais que uma expressão de uma interpretação imposta ao presente de sua produção e ao futuro. Para Le Goff (1994), documento é monumento. Não é neutro, muito menos imparcial. É uma concepção sustentada por interesses e pontos de vista. Neste 
caso, acrescenta-se aqui, tem uma posição política e moral. Entretanto, em função de uma ideia ainda vigente de que só é válido se sustentado na neutralidade e imparcialidade, a política e a moral são negadas ou escondidas no discurso de que está se fazendo algo em função do bem comum.

As políticas públicas de preservação do patrimônio cultural acabam encampando esta negação da política e da moral, entendendo o tombamento como um processo de monumentalização do espaço e de práticas territoriais que tendem a ser vistas como cristalizadas no lugar, representando a todos. Para fortalecer ainda mais esta ideia, a monumentalização da cidade veio acompanhada de uma série de intervenções urbanísticas visando racionalizar espaços, organizar fluxos e atribuir novas definições funcionais a determinadas áreas e equipamentos. As modificações urbanas na cidade são justificadas pela gestão pública dentro da concepção de uso racional e estético, tendo em vista, também, um suposto conforto de um morador genérico chamado de sobralense, sendo fortes os argumentos da sintonia entre o novo e o antigo - moderno e tradicional - e da eficácia de funcionalidades específicas para os espaços.

Herzfeld (1991) chama atenção para a influência do estado e seus instrumentos jurídicos e educacionais na formulação de uma identidade para o local, percebe que há disputa entre ideologias diferentes que servem como base para se pensar a origem para a cidade. Estas disputas mostram ambiguidades entre o "tempo monumental" do discurso oficial e o "tempo social" do cotidiano. Este discurso oficial, geralmente, transforma algumas propriedades pessoais em monumentos coletivos, causando uma série de constrangimentos legais aos moradores no que se refere à impossibilidade de reformas em suas casas. Em Sobral, está sendo comum a tensão entre interesses de moradores do sítio histórico em modificar suas propriedades e a visão dos técnicos do IPHANxii.

Não é recente, muito menos um caso exclusivo de Sobral, esta preocupação com o patrimônio histórico e cultural pelo Estado. Henriques (2004) chama atenção de que o interesse pela discussão sobre a cultura enquanto preocupação de políticas de desenvolvimento, tem três justificativas. A primeira remete ao valor identitário que o patrimônio cultural carrega consigo. A relação entre o local e extralocal, dependem desta preservação, pois conferem caráter aos lugares, diferenciando-os uns dos outros. O avanço da urbanização promovido pela globalização é que promove uma nova sensibilidade a está matéria, segundo Henriques (2004), pois constrói uma sensação de ameaça à diversidade. Isso remete à segunda razão que invoca a atenção pelo patrimônio cultural, que é a sua influência na construção da coesão dos grupos sociais através do sentimento de posse aos lugares, ajudando a desenvolver o sentido de comunidade. Por fim, a terceira, e não menos importante, razão pela qual a cultura passou a ser foco do Estado é o entendimento de que a salvaguarda do patrimônio cultural é valiosa como forma de abertura para o desenvolvimento econômico, seja na área rural, seja na área urbana, pensando o turismo. A atração pelo lugar pode promover novos investimentos em setores diversificados e qualificados da economia, sendo fator de competitividade entre os territórios. O centro urbano de Sobral e seu entorno é o lócus privilegiado para o investimento das políticas públicas neste sentido. O remanescente faz parte da cidade, que também recebe assistência, mas de outra ordem, como assistência social, saúde, educação, dentre outras, mesmo que de forma precária.

O tombamento de parte da cidade como Patrimônio Histórico Nacional tende a transformar o sítio histórico tombado e determinadas manifestações culturais em documento que tem o objetivo de registrar uma história exemplar e formalizar uma versão como única possível. Podese supor uma leitura que tenta mostrar os distintos elementos, suas articulações e pronúncias, reconstruindo e reinterpretando o sentido implícito e explícito na composição da narrativa ufanista que tem a pretensão de falar de todos os sobralenses escamoteando a pluralidade da cidade e acobertando alguns interesses e pontos de vista. Não se quer crer que isso seja suficiente para dar conta da riqueza inumerável de passagens, circunstâncias e elementos fornecidos pelas percepções e afecções possíveis que a cidade e sua monumentalização podem oferecer. Entendam a crítica aqui feita como uma versão de afetos resultante de uma experiência compartilhada com moradores da cidade e suas imagens produzidas, além de interpretação de fontes documentais. $\mathrm{O}$ articulista vive na cidade e acompanhou de perto este processo de monumentalização que, em 2019, segundo a gestão municipal, fez 20 anos, já que, apesar do registro ter sido publicado em 2000 no livro de tombo no IPHAN, a oficialização do tombamento foi aprovada em 1999. Justamente por isso que se percebe a parcialidade da narrativa sobre a "Sobralidade triunfante". Não é falsa ou mentirosa esta narrativa, mas precisa ser sustentada na ideia de que mostra uma unidade cultural, mesmo que seja fictícia.

Além disso, a analogia da monumentalização com o documento permite entender que a tradição selecionada, que justifica 
esta ação no centro da cidade, não é contraditória nem representa uma ruptura quando casada ao termo "moderno" que a administração encabeçada por Cid Gomes atribui a si mesma. Desde a primeira gestão, entre 1997 e 2000, os "Ferreira Gomes" expõem estes termos como marco de distinção, misturando a ideia de tradição e de modernidade. Evidentemente, ressaltando mais o segundo termo, já que a tradição tem relação com uma narrativa que entende a história de Sobral como tendo a vocação para ser moderna, mesmo que este conceito não esteja sendo detalhadamente explicitado.

A forma de intervir no espaço urbano, especialmente no centro, local da cidade onde situa-se o sítio histórico tombado, mostra bem essa ideia do que significa a modernização, assim como a preservação da tradição para os "Ferreiras Gomes". Para fins de entendimento, vale a pena lembrar que Silva (2000) define o que é patrimônio, entendendo-o como uma construção social, resultante de uma composição de um corpus cultural difuso e sujeito a uma engenharia social que lhe dá sentido e significado. Não é espontâneo, nem natural e muito menos universal. É uma operação ou agenciamento estratégico com um propósito ou finalidade que depende das relações de força postas em tensão no cotidiano, por distintos sujeitos sociais que compõem a cidade e disputam o poder político e econômico. A qualificação do lugar como patrimônio cultural é uma idealização ativada por uma dimensão utilitária, moderada por um valor de identificação simbólico, eficaz e estratégico para criação de uma imagem de defensor da cidade. Erige fronteiras, trajetórias e tradições diferenciadoras para quem prega esta ideia, dando uma significação especial ao seu objetivo, passível de flutuações da moda e de critérios matizados pelos agentes culturais, intelectuais, políticos e econômicos em tensão ou diálogo.

Esse agenciamento e construção do que é o patrimônio e a tradição são materializados e justificados por uma concepção de ideal público da imagem do agente, que tende a evidenciar uma intervenção imediata e supostamente incontestável da tecnocracia que domina como agente político, atrelada aos órgãos institucionalizados, para atender às demandas ditas como se fossem coletivas sobre o assunto. É um ideal pautado em um passado construído e legitimado pelo perito que é usado pelo agente político, que emana uma visão essencialista, neutralizando contingências, circunstâncias e contradições que possam ser suscitadas pelos rivais. Acrescenta-se aqui que o passado, neste aspecto, passa a ser usado como uma utopia a ser alcançada ou um desejo de identidade coletiva e de lugar, a ser aplicado no presente. Isto justifica a necessidade de preservação, porque ela, supostamente, ensina como devemos ser hoje, para termos um futuro melhor. O patrimônio histórico tombado lembra de uma moral relacionada a uma identificação especial do que é ser sobralense, como é o caso aqui analisado. É um marco espacial que é colocado como modelo de imperativo moral que não deve ser desrespeitado.

Silva (2000) também chama a atenção de que a história contada e criada para o patrimônio é uma ficção que organiza uma narrativa do mito de origem, ressaltando continuidades exclusivas e dotando um grupo seleto de prestígio. A monumentalização, portanto, é um instrumento eficaz para os propósitos políticos e morais de quem o aciona, como podemos ver no caso de Sobral, emanando visões monolíticas, objetivando a adesão popular para legitimar sua forma de ver e entender a ação no espaço urbano. Propósito este que é impulsionado, maximizado e matizado de forma insistente e eficaz por incentivos financeiros públicos existentes para o setor, e pelo sistema jurídico que promove a proteção daquilo que, só na aparência, é coletivo. No caso do que acontece em Sobral, vale a pena perguntar: será que todo sobralense pensa a mesma coisa sobre seu patrimônio?

Foi esta questão que levou o articulista a se interessar pelo tema, uma vez que, como morador e pesquisador, acompanhou a campanha política de 1996 e o processo de tombamento, como já dito, e dá continuidade neste trabalho no Laboratório das Memórias e das Práticas Cotidianas - LABOME da Universidade Estadual Vale do Acaraú - UVA - Os técnicos contratados no início da produção do Processo de Instrução eram seus colegas de trabalho e teve a oportunidade de estar próximo deles na identificação das fontes primárias de pesquisa e na elaboração do estudo técnico. Sendo morador e pesquisador, viu o sítio histórico sendo tombado, entrevistou gestores do município, do IPHAN e moradores deste espaço, assim como acompanhou as intervenções urbanísticas e eventos públicos de inauguração dos espaços modificados. $\mathrm{O}$ articulista também acompanhou as notícias na imprensa e teve a oportunidade de estar em algumas discussões em eventos da cidade que tinham como objetivo pensar o modelo de preservação a ser adotado.

As campanhas eleitorais que sucederam a de 1996 também foram focos de atenção do pesquisador, já que anunciavam pistas para se pensar o que acontece em Sobral. Entendendo todo este processo como agência no campo político e moral é que se passa aqui mostrar como 
isso acontece em Sobral, na perspectiva da gestão da cidade, no campo das políticas públicas de urbanização e de educação patrimonial, selecionando duas fontes documentais principais que são implicações das agências políticas da gestão municipal no sentido de criar uma ficção de unidade cultural para melhor disciplinar a gestão da cidade, potencializando a força política daqueles que ocupam a Prefeitura Municipal.

\section{Patrimônio-monumento: imposição de unidade cultural e de lugar na cidade}

O que acontece em Sobral e na maior parte dos sítios urbanos tombados é uma imposição de unidade do patrimônio que identifica o lugar. $O$ quase-grupo xiii político encabeçado pelo ex-prefeito, ex-governador e senador Cid Gomes - PDT - e seus irmãos demonstra em suas ações e prioridades saber da eficácia ao valorizar esse instrumento. A monumentalização da cidade não é uma política isolada de um conjunto mais amplo de intervenção técnica na paisagem planejada pela municipalidade. A justificativa desta transformação na paisagem é a política pública de preservação, o que não é um movimento específico do caso de Sobral. O que é específico em Sobral é o tipo de capitalização política que a administração municipal faz desta política pública. O Plano Diretor de Desenvolvimento Urbano PDDU - parece expressar bem esta intenção. O livro didático adotado pelo sistema de ensino fundamental da cidade chamado "Descobrindo e construindo Sobral: conhecimentos de Geografia e História" parece também ser fonte significativa para visualizar a estratégia adotada pela política municipal no sentido de construir e alinhar disposições ordenadas de maneiras de ser e ver a realidade histórica e geográfica de Sobral. Maneira de ver esta que compõe um caráter e estilo de definir o que é a cidade, o perfil de cidadão, enfim, uma identidade sobralense, qualificada como "sobralidade triunfante".

$\mathrm{Na}$ primeira gestão de Cid Gomes ocorreram esforços para criação do Plano Diretor de Desenvolvimento Urbano - PDDU -. Estes esforços geraram, no ano de 1999, a Lei Complementar no 5 de 1 o de fevereiro de 2000. Este processo, refeito e revisto em função da criação do Estatuto das Cidades por parte do Governo Federal (Lei Federal no 10.257 de 10 de julho de 2001), gerando a Lei Complementar de no 28 de 15 de dezembro de 2008xiv, é adotado pela Prefeitura para o planejamento estratégico, que visa constituir-se como um instrumento de gestão urbana, contém diretrizes e políticas que devem ser adotadas pela municipalidade, e seu texto informa que foi elaborado de forma participativa, não restringindo as orientações de ações à gestão municipal. Qualquer instituição governamental ou não governamental pode utilizar deste instrumento para tomar decisões que digam respeito ao "interesse público na cidade". O relatório que antecede e fundamenta a lei, gerado para a versão do PDDU de 1999, faz uma caracterização da cidade nos aspectos físicos, territoriais, ambientais, socioeconômicos e urbanísticos. Concentra-se a leitura neste texto em função da sua riqueza de detalhes. Ele começa com uma epígrafe que diz o seguinte:

$$
\text { A CID ADE QUE QUEREMOS... }
$$

Uma cidade com alto nivel de acessibilidade social aos bens $e$ aos serviços para todos os seus moradores, realcando sua berança bistórica, preservando seu ambiente natural e promovendo o conforto da vida urbana com justiça e eqüidade (Relatório de Questões / Módulo conceito, 1999, p. 4).

A epígrafe é um anúncio de metas que vão orientar todo o documento. $\mathrm{Na}$ sua primeira parte, o documento apresenta a história urbana da cidade. Nota-se que a geração de riquezas aparece como destaque nesta história. $\mathrm{O}$ mito de origem é contado a partir de fazenda pecuarista, lembrando o entroncamento de caminhos das boiadas que, ou são comercializadas no local ou passam em direção a outras regiões. $\mathrm{O}$ entroncamento destes caminhos fez surgir o primeiro núcleo urbano. O comércio do gado passa a ser explicação para geração de riquezas em Sobral, somado à afirmação de que o morador deste tempo colonial possui relações próximas com outras regiões do país e do exterior, o que serve no documento para exaltar a influência econômica exercida pelos moradores prestigiosos da cidadexv. Segundo o que diz o documento:

Por força da condição estratégica de convergência comunicacional na região (encruzilhada de vários caminhos regionais), seus habitantes pertencentes à elite, passaram então a ter acesso às informações oriundas das regiões mais ricas do pais e, indiretamente, de outros continentes, o que gerou comportamentos civilizados na elite local, como o gosto pelas artes. [...] Tudo isso fez de Sobral um importante centro regional, hoje a maior cidade da zona norte do Estado. Seu raio de influência chega a atingir um conjunto de cidades a uma distância 
de $200 \mathrm{~km}$. As estradas de acesso que convergem ao Município e a Cidade de Sobral se configuram em rodovias federais e rodovias estaduais, confirmando as linhas de desejo da população regional, existentes desde o periodo da colonização $e$ acentuada nos dias atuais (Relatório de Questões / Módulo conceito, 1999, p. 15).

O documento mostra que a influência econômica, portanto, não é somente uma característica de seus primórdios, mas tornou-se uma tradição local que deve ser digna de registro e comemoração. As edificações representativas do refino e requinte de uma elite são lembradas para destaque. É lembrada também a importância da Igreja Católica, como instituição corresponsável pela constituição dos primeiros aglomerados urbanos, localizados ao redor da Matriz e, posteriormente, na Igreja do Rosário. Não se deixou de lado o comerciante como agente fomentador da transformação urbana. Portanto, três tipos de agentes sociais compõem o elenco dos protagonistas desta geografia histórica contada pelo documento: o clero, o comerciante e o pecuarista.

A história registrada no PDDU, assim como o que acontece no Processo de Instrução enviado ao IPHAN, é contada por ciclos econômicos, ressaltando a fase do algodão e da industrialização como posteriores ao da pecuária. As edificações que ganham destaque neste documento, geralmente da elite da cidade, vão aparecendo na narrativa como resultantes destes ciclos. A estrada de ferro, que hoje delimita boa parte da região do entorno do centro histórico tombado, principalmente o seu trecho que sai de Sobral rumo à cidade de Camocim, finalizado em 1882, que não existe mais, a cadeia pública de 1879, o Teatro Apolo de 1876 e o transporte de bonde puxado por burro representam o ciclo do algodão, que antecipa ao da industrialização, marcado pela construção da Fábrica de Tecidos Ernesto Deocleciano, inaugurada em 1887. Chama para destaque a inauguração do Teatro São João em 1885, quando "a integração dos espaços urbanos se fazia por novas avenidas, alargadas, quando a cidade alcançou sua melhor qualidade espacial" (Relatório de Questões / Módulo conceito, 1999, p. 19).

O ciclo da industrialização no século XX é lembrado no documento como marca temporal de transformações urbanas substanciais, produzindo novas expansões com relação à ocupação do solo, apesar de não haver incremento muito grande na quantidade total da população. A adoção do Código de Posturas de Sobral, na primeira metade do século XX, marca um outro tempo no documento. É um tempo pessoalizado no bispo
Dom José Tupinambá da Frota, quando a Diocese de Sobral, segundo o documento, substitui a iniciativa da gestão pública, na construção de edificações e equipamentos como bancos, escolas, museu, jornal e hospitais xvi. Neste tempo, as relações com Fortaleza, capital do estado, são facilitadas com a conclusão da estrada, não precisando mais dos portos de Camocim ou Acaraú para o transporte de pessoas e mercadorias. Esta é a década de 1950, quando começam a surgir as primeiras moradias das novas elites no campo econômico e político, fora do, contemporaneamente, centro histórico tombado. $\mathrm{Na}$ década de 1970 e 1980, este movimento faz surgir bairros como Junco, Colina e Derby Club (onde já existia o hipódromo), que abrigam estes abastados moradores. A população pobre também acompanha este movimento para a periferia, ultrapassando o trilho e o rio que circundam o centro histórico, aparecendo bairros como Dom Expedito, Sumaré, Sinhá Sabóia, Padre Palhano, Terrenos Novos, dentre outros.

A versão da história informada pelo documento se repete em outras fontes é é difundida de forma simultânea por outros instrumentos. O próprio documento sugere esta possibilidade como uma iniciativa necessária da política pública de educação. O livro didático é um instrumento eficaz para este fim. Neste sentido é que foi publicado o livro "Descobrindo e Construindo Sobral: Conhecimentos de Geografia e História", adotado em 2002 nas escolas municipais e produzido por professoras da Universidade Estadual Vale do Acaraú.

O livro didático começa tratando sobre o patrimônio histórico de Sobral, ressaltando o tema da riqueza e importância regional da cidade. Além deste tema, na parte destinada ao conteúdo da história, destaca a independência de Sobral com relação à capital até meados da década de 1920 . Lembra também dos primeiros nomes, Vila Distinta e Real de Sobral - no Brasil colonial -, que remetem à origem lusitana de muitas das famílias instaladas nesta época. Sobre isso, o livro informa que: "Dizia-se que era uma Vila Distinta, por ter se originado dos colonizadores portugueses. Sobral foi a única vila do Ceará a ter essa qualidade. Diziase que era Real, por ter sido criada por ordem direta do El-Rei D. José I" (Caracristi \& Saboya, 2002, p. 95).

Contemporaneamente, parece que o ato e o efeito da distinção atribuída ao nome da então vila, remetem a um conjunto de qualidades sociais superiores, um agraciamento que se aproxima de honraria ou condecoração de ser um território ocupado pelo colonizador em detrimento do tipo de habitante que seria peculiar ao lugar. A ideia que 
se passa é que o padrão civilizador do colonizador, supostamente o primeiro a chegar na região que hoje ocupa a cidade, é indício de que, desde os primórdios, o que tem de "melhor no mundo" chega aqui. A imagem que se passa do colonizador remete a uma qualidade e possibilidade de educação apurada, por não ser mestiço. Tenta mostrar também uma nobreza de porte, correção de procedimento e elegância próprios de imagens ainda hoje correntes sobre o que seriam os europeus, ou, simplesmente o que é estrangeiros, entendendo-os como superiores. Não é à toa que a data do reconhecimento do aglomerado urbano como vila é mais comemorado do que o seu reconhecimento como cidade em 1841. A proximidade da independência norte americana comemorada no dia 4 de julho - no calendário anual -, um dia antes do reconhecimento de Sobral como vila, também favorece esta preferência, ressaltando ainda mais a distinção através da ideia, correntemente comentada no cotidiano da cidade, da influência estrangeira que faz com que seja chamada de United States of Sobralxvii.

O livro também fala da presença indígena na região e da escravidão, sempre lembrando espaços e objetos dos bens tombados nos dias de hoje, que remetem a estes temas. Sobre o indígena, lembram da história contada sobre o embate com os colonos, que houve no local antes chamado Fortaleza, que abrigava a Fábrica de Tecidos Ernesto Deocleciano, até a década 1990, e, contemporaneamente, é campus da Universidade Federal do Cearáxviii. As autoras lembram que lá existia, antes da construção da fábrica, inscrições rupestres destruídas com a implantação da edificação fabril. A escravidão é lembrada nas suas formas de exploração do trabalho em Sobral. Lembram que seus donos eram carregados por eles em liteiras. Alguns destes meios de transporte, do final do século XIX, hoje integram o acervo do Museu Dom José, instalado em uma edificação no centro históricoxix.

O Museu Dom José, por sua vez, é sempre lembrado nas publicações impressas e virtuais sobre ele, como um dos mais importantes acervos de arte sacra do país, exaltando o pioneirismo e distinção da cidade comparada às demais no âmbito cearense. A história que os guias do museu contam para o público, na visitação, é que Dom José, pessoalmente, conseguiu boa parte de acervo junto a Igrejas e capelas da regiãoxx. O livro didático adotado nas escolas do ensino fundamental de Sobral, também reproduz esta mesma ideia. Outro monumento importante lembrado pelo livro didático é a Igreja de Nossa Senhora do Rosário, quando se fala da escravidão. O livro informa que a Igreja foi edificada em 1760, pela Irmandade de Nossa Senhora do Rosário dos Pretinhos, constituindo um segundo núcleo urbano na cidade. A Irmandade era organizada por exescravos, ela realizava a festa dos Reis Congos até o ano de 1879xxi. O livro informa que a escravidão também criou suas lendas e heroínas, como a escrava Romanaxxii, morta por capitães do mato na serra da Meruóca e Maria Thomázia xxiii, fundadora da Sociedade das Senhoras Libertadoras.

Dom José Tupinambá da Frota, também é lembrado pelas autoras:

Com a criação a Diocese de Sobral, em 1915, tendo como seu primeiro bispo Dom José Tupinambá da Frota, a cidade acelerou o sen desenvolvimento, quando foram fundados: Seminário, Santa Casa, Colégio Sant'Ana, Colégio Sobralense, Museu, Abrigo para Idosos, o jornal Correio da Semana, Banco Popular de Sobral, dentre outros (Caracristi \& Saboya, 2002, p. 105).

Esta citação parece acrescentar a ideia dos ciclos econômicos e, neste sentido, a história de Sobral parece ter quatro tempos em destaque, sempre frisando a opulência e excelência da cidade. $\mathrm{O}$ primeiro remete à origem, lembrando o primeiro núcleo urbano. Ele surge em função da economia da pecuária, dando distinção aos primeiros moradores. O segundo, faz menção ao século XIX, com a economia do algodão e início da industrialização. O terceiro tempo é personalizado nas agências da diocese, através do bispo Dom José. É curioso como a força política de uma pessoa pode ser considerada como ciclo econômico da cidade, mesmo não ocupando um cargo tradicionalmente associado à carreira política, exceto o fato de ter sido Bispoxiv. Finalmente, o quarto ciclo que parece ser apontado no livro, tem relação com o governo municipal de Cid Gomes período 1997/2004, fazendo sucessores até 2020 -. O livro versa que: A partir da década de 1990, Sobral retomou o
seu crescimento, com a chegada de novas
indústrias, com o crescimento da Universidade
Estadual Vale do Acaraú e da Santa Casa de
Misericórdia, contribuindo para o impulso
modernizador implantado pelo governo municipal
que vem transformando a cidade (Caracristi \&
Saboya, 2002, p. 107).

A década de 1990 é marcada, exatamente, pela "troca-troca" de prefeitos entre 1992 e 1996, já mencionada aqui, e a vitória de Cid Gomes nas eleições de 1996. Talvez o livro esteja se referindo ao final da década de 1990, já que a gestão anterior a 1996 provoca um caos administrativo na cidade. 
A Universidade Estadual Vale do Acaraú e a Santa Casa, lembradas na citação e, na história contada no livro, relacionadas ao "tempo" de Dom José, são responsáveis por um intenso fluxo de pessoas oriundas de outras cidades que não têm acesso, em seus lugares de origem, ao tipo de serviços prestados por estas instituições. Entretanto, o que mais chama atenção nesta passagem não é isso. É a exaltação do tempo da retomada do "crescimento" e o "impulso modernizador" atribuído ao governo Cid Gomes. As mudanças no centro da cidade são fundamentais para entender melhor esta exaltação. É nele que se aplica a política de monumentalização, justificada também por intervenções registradas como modernas.

Não são somente as edificações antigas que lembram da excelência e opulência do “sobralense". O Museu do Eclipse, por exemplo, é uma edificação inaugurada em 29 de maio de 1999. Este museu remete a lembranças avaliadas como fundamentais pela monumentalização, mesmo sendo recente, pois ressalta um evento que fala da importância da cidade, não só no âmbito regional, estadual ou nacional, mas também internacional. $\mathrm{O}$ evento foi o eclipse que serviu como fonte para experimentos que comprovaram empiricamente a teoria da relatividade de Einstein, como já lembrado neste artigo. O livro didático analisado explica o motivo da escolha de Sobral para o experimento. Segundo a explicação, o clima e a localização favoreceram uma boa observação do eclipse solar ocorrido em 1919, comprovando a curvatura da luz, proferida na teoria. No museu estão réplicas dos equipamentos usados, fotos, notícias de jornais da época, inclusive de periódicos internacionais como o New York Times xxv . A edificação foi construída no mesmo local da observação. O museu tem o formato de duas meias luas, com as faces internas viradas uma para a outra. A proposta arquitetônica é de reproduzir a imagem de arcos de luz que escapam pela borda da lua no momento do eclipse. No centro do museu está um monumento de simbologia republicana, especificamente jacobina, lembrando a passagem de Sobral da condição de vila à cidade em 1841. Além disso, um planetário e um telescópio foram instalados na edificação. No lado oposto, está uma réplica do antigo monumento que existia na praça, antes da construção do Museu, lembrando o evento.

A escultura de mulher, com um barrete frígio, de braço erguido, inaugurado em 7 de setembro de 1927, foi usada para lembrar a passagem de Sobral à condição de cidade. Esta e o museu são monumentos sobrepostos que lembram épocas e motivos diferentes, há uma forte relação significativa entre eles. Um dos significados possíveis que podem ser pensados na relação é a expressão da necessidade de mostrar que a cidade, simbolizada no monumento de seu reconhecimento, possui uma excelência, pois ajudou ao mundo na comprovação de uma grande teoria, que, de certa forma, influenciou fortemente, não só mudanças de concepções no campo científico, mas também no campo comportamental, político, dentre outros. Segundo o que noticia o Jornal Municipal, "[...] o Museu existe para mostrar a todos os seus visitantes que Sobral tornou-se palco de um dos mais importantes episódios da ciência mundial" Jornal Municipal de maio/junho de 2003).

Em 29 de maio de 2015 foi inaugurado, ao lado do Museu, o Planetário de Sobral, reforçando a história que conta o evento mencionado. $\mathrm{O}$ complexo que engloba Museu, monumento que lembra o reconhecimento da cidade, Planetário, exalta ainda mais a versão da História contada pela política de monumentalização, porém alargando os limites da narrativa sobre a excelência e o pioneirismo atribuídos à cidade, não mais definindo comparações regionais e nacional, mas também, mundiais.

$\mathrm{Na}$ época da inauguração do Museu, vários eventos foram realizados, dentre eles, um seminário organizado pela Universidade Estadual Vale do Acaraú, que contou com a presença do astrônomo Ronaldo Rogério Mourão, do Observatório Nacional do Rio de Janeiro. Ele enfatiza o pioneirismo da cidade em seu discurso. Uma boa parte do secretariado municipal estava no evento, além do Reitor da Universidade Estadual Vale do Acaraú e do Prefeito; seus discursos também continham um claro conteúdo ufanista. $\mathrm{O}$ astrônomo deixou um autógrafo no livro de visitas do Becco do Cotovelo xxvi, com a seguinte mensagem:

[...] Sobral, cidade internacionalmente conhecida, onde em 29 de maio de 1919, inicion-se o século XX. A confirmação em Sobral da teoria da relatividade teve uma enorme influência no abandono de todos os padrões absolutos, quer morais on filosóficos de um mundo que emergia para o relativismo moral que provocou o abandono dos padrões rígidos na música, na literatura e nas artes a partir dos anos 1920. Sobral é um dos orgulhos dos brasileiros (Livro de autógrafos do Becco do Cotovelo, 5 de maio de 1999).

Esta narrativa exalta e destaca a cidade no cenário internacional, que foi reeditada no evento que comemorou os 100 anos do eclipse mencionado, em 2019. Este evento reuniu 
autoridades nacionais e internacionais do campo da física, astronomia e do Governo Federal, inclusive o Ministro da Ciência, Tecnologia e Comunicação xxvii. O ufanismo é exaltado nestas lembranças, e a cidade passa a ser merecedora de narrativas que falam do sentimento de orgulho, não só para o sobralense, mas para todo brasileiro e até para o mundo. Para o astrônomo carioca citado, Sobral contribuiu para a confirmação de uma teoria científica responsável por mudanças radicais no comportamento e na forma de entender o mundo ao nosso redor. Porém, não é só a cidade que é lembrada por conta da edificação deste Museu. Em outro momento, no artigo publicado no jornal "O Povo", reproduzido pelo Informativo da Prefeitura "Sobral no rumo certo", o então senador Lúcio Alcântara argumenta que: sensibilidade do prefeito de Sobral, Cid Gomes, que oportunamente recuperou a memória das circunstâncias que envolveram o episódio, difundindo-o em seus detalhes e destacando sua importância como referência cultural para a história daquela cidade, já tão marcada por fatos relevantes e personagens de exemplos incomuns. Cid edificou um museu, onde reuniu equipamentos $e$ materiais utilizados pelos astrônomos. Movimentou, enfim, a sua comunidade em volta de uma referência circunstancial, é verdade, porém marcante para o desenvolvimento do conbecimento bumano. $O$ que cabe aqui ressaltar é a importância que tem para o êxito de uma gestão, em qualquer nivel e de qualquer natureza, a aplicação dos recursos da criatividade, que muitas vezes supera carências e emite sinais de estímulo e vigor sem passar necessariamente por gastos muito elevados. A sintonia do gestor com os aspectos construtivos da identidade coletiva daqueles a quem lidera tem a "qualidade" de despertar forças subjetivas e potenciais intangiveis, direcionando, com senso de oportunidade e valorização do talento nativo, os melhores estímulos na direção do desenvolvimento concreto das condições materiais de vida" (Informativo Sobral no rumo certo, 13 de agosto de 1999).

Desta forma, o então senador ressalta não só peculiaridades significativas do município, mas também de seu gestor que, segundo sua versão, está sensível aos anseios de afirmação de uma identidade coletiva potencializada por esta obra. Este depoimento pretende coroar não só uma cidade, mas também uma forma de ver e agir na cidade por parte de seu gestor. Apesar de o referido senador, em 2006, ter concorrido a reeleição como governador pelo PSDB, exatamente contra Cid Gomes, na época pertencente aos quadros do PSB. O interessante nesta disputa de 2006, especialmente nos programas televisivos da campanha dos candidatos opostos que concorriam ao cargo de Governador do Estado do Ceará, é que Sobral virou o foco de atenção da campanha. Por um lado, o então governador Lúcio Alcântara, criticava as ações de Cid Gomes em Sobral, falando também dos investimentos do Governo do Estado nesta cidade. Por outro lado, Cid Gomes falava de seus feitos na cidade e criticava a atuação do então governador.

Ao ser vitorioso nas eleições de 2006, Cid Gomes consegue se reeleger em 2010 pelo PROS e faz seu sucessor Camilo Santana, do PT. Mesmo sendo de outro partido, Camilo teve forte apoio dos irmãos "Ferreira Gomes", se reelegendo em 2018 para seu segundo mandato, ainda apoiado por eles. A estratégia de anular as oposições a partir de alianças pessoais com políticos de diferentes partidos, fez com que o quase-grupo político venha se sustentando no poder, não só em Sobral, mas também no governo do estado. As lembranças do que Cid Gomes e seus sucessores fizeram, no que se refere à valorização da cidade e ao exemplo de gestão pública, sempre são acionadas nos momentos de campanha eleitoral, o que parece ter forte adesão dos eleitores. A política de preservação do patrimônio histórico, e seu investimento em construir uma unidade para o que se define como "sobralidade", certamente favorece esta manutenção no poder e vem sendo reproduzida nas demais áreas, como visto aqui os exemplos de instrumento de planejamento urbano e educação. É comum pensar a política de preservação do patrimônio histórico atrelada ao incremento do turismo, entretanto, em Sobral, o ganho neste setor foi pouco significativo. Entendese aqui que o ganho foi muito mais político no sentido de fortalecer um determinado quase-grupo no poder e ampliar o seu foco para o âmbito estadual, do que econômico, no sentido do fortalecimento do turismo cultural.

A análise de indicadores econômicos talvez possa ser foco de outro artigo, mas, aqui, o esforço foi muito mais o de compreender como uma narrativa ufanista tem relações com interesses políticos e morais de como fazer a gestão da cidade.

\section{Conclusão: $O$ centro como expressão de diversidade e convergência de práticas - alguns contrapontos críticos}

É preciso acrescentar alguns elementos às reflexões aqui feitas para chegar-se às considerações finais. Primeiro, é preciso pensar que o centro, especialmente o que corresponde ao sítio histórico tombado da cidade de Sobral, não é tão 
diferente do movimento das áreas centrais das grandes metrópoles como São Paulo, Rio de Janeiro ou mesmo Fortaleza, guardando as devidas proporções demográficas. Comporta em seu ambiente, durante o dia, espaços em que os indivíduos se aglomeram e se movimentam em agrupamentos aparentemente caóticos, tornando cada transeunte um anônimo no meio do confuso, do ruidoso e do agitado movimento. A caminhada nestes locais não flui da forma que o transeunte quer. Os passos são constantemente suspensos por barreiras humanas que transitam em sentidos opostos. Este movimento intenso é claramente visível, não só nas proximidades do Becco do Cotovelo, como também nas proximidades do Mercado Central. Contraditoriamente, dependendo do horário, alguns focos isolados destes mesmos espaços podem perder sua intensidade de movimento, tornando-se singelos pontos de encontro de famílias e vizinhos nas calçadas das casas ao entardecer. As motivações de cada transeunte são inúmeras. Poucos visam contemplar o centro como monumento representativo da identidade coletiva do sobralense. O fluxo maior é no comércio, serviços públicos ou bancários.

Diante destas observações, penso que não é possível estabelecer uma funcionalidade fixa a este espaço enquanto tradicional ou relacionado a lembranças da história da cidade. Isso porque os habitantes, criativamente, refazem itinerários e práticas cotidianas, não permitindo visualizar somente rotinas, tradições e histórias que remetem a um perfil de "sobralidade". Na versão do PDDU é chamada a atenção para este problema, porém somente no aspecto das formações e revestimentos da estrutura urbana e das edificações, na flexão destas formas com relação às diferentes maneiras, quase orgânicas, de funcionar. Consequentemente, o documento apresenta estas interações funcionais como distantes e dissociadas dos agenciamentos, vontades, desejos, sonhos e devaneios dos sujeitos sociais que compõem o ambiente.

Este documento aborda, por exemplo, do centro como a parte mais representativa da cidade - do ponto de vista da cultura, do comércio e dos serviços -, sem desistir de sua funcionalidade enquanto moradia. $\mathrm{O}$ crescimento do comércio e dos serviços, segundo o PDDU, vem provocando mudanças na utilização das edificações e demolição de algumas delas, mostrando que o "tempo monumental" pode ser importante para alguns habitantes, especialmente àqueles vinculados ao poder público, mas não para todosxxviii. Como já dito, lembrando Herzfeld (1991), há sempre uma distância entre o "tempo monumental" e o "tempo social". Acrescenta-se aqui uma distância entre o "espaço monumento" e o "espaço social" do cotidiano.

Esta distância entre "tempo monumental" e "tempo social" nos faz pensar que não é possível conhecer e compreender a vida urbana em uma determinada cidade e sua identidade coletiva somente levando em consideração sua dimensão funcional. $O$ PDDU analisa a cidade na sua dimensão funcional: como uma descrição de um quadro físico, que esquece a prática socioespacial dos agentes - individuais e coletivos -, mesmo que ele venha a remeter, em alguns momentos, ao que sugere o processo de instrução que culminou no tombamento da cidade como patrimônio histórico - sugerindo uma espécie de unidade cultural -. Não se pode pensar que exista uma unidade cultural dos habitantes no que se refere a identificação de uma "sobralidade". Parece haver uma espécie de naturalismo na descrição da cidade, entendida como um meio ambiente, onde a vida humana é simplificada em modelos, como conjuntos de qualidades externas que cercam as pessoas, que são restringidas a meros "usuários" ou "público alvo" de determinadas atitudes, o que se deve relacionar a um possível ganho de "qualidade de vida" pregada no documento. Portanto, desconsidera as tramas, agenciamentos vontades inumeráveis e imprevisíveis dos sujeitos sociais praticantes do espaço.

Isso acaba tendo implicações na própria forma de contar a história da cidade e falar da identidade cultural. $\mathrm{O}$ inusitado, por exemplo, não é somente considerar as mudanças do espaço urbano como funcionais das edificações, em decorrência das demandas comerciais em um tempo linearmente marcado pela ideia do desenvolvimentismo econômico, mas também desconsiderar os distintos modos de praticar o espaço por parte de seus usuários que não podem ser definidos por territorializações, práticas e tempos lineares e previsíveis, como é o caso da identidade coletiva pensada como unidade e homogeneidade na política de preservação do patrimônio histórico. Supõe-se aqui que não é possível pensar em um encargo identitário definitivo para qualquer espaço social ou para qualquer identidade coletiva. Há também desorientações, reorientações e ações distintas e indefinidas no cotidiano que desterritorializam aquilo que parece estável. As pessoas não só usam, ou consomem, ou se beneficiam com ações públicas pautadas em preceitos e planejamentos tecnocráticos, elas criam práticas dentro de limites e possibilidades próprias das relações sociais e dos códigos que dominam para promover 
desterritorializações e territorializações no lugar que usam e criam.

Entende-se identidade como um desejo, no sentido deleuziano do termo. Parafraseando Deleuze (1997), desejo é agenciamento de um conjunto de elementos que inventam o objeto supostamente referente. De fato, para o filósofo citado, não se deseja uma identidade, mas uma série de elementos que compõem um conjunto relativo ao lugar, a posição, aos interesses e imagens que circundam o "ser" desejado. Nesta concepção, devemos nos ater a engenharia social construída pelos agentes individuais para falar e agir em prol de um movimento de sua constituição que é constante, flexível e instável, dependendo do contexto de comunicação em que cada agente atua.

Para exemplificar a força do desejo, o articulista já ouviu depoimentos de pessoas vinculadas ao poder público, preocupadas com a falta de interesse do morador da periferia da cidade em visitar os equipamentos culturais presentes no sítio histórico. A questão deveria ser invertida. $\mathrm{O}$ morador da periferia que não frequenta os equipamentos culturais do sítio histórico talvez não se identifique com a narrativa oficial sobre a "sobralidade", pois esta não parece gerar nenhum tipo de afinidade. A questão é: por que não se pensa a cidade com plural? Por que não se pensa a identidade como conceito que tem uma relação muito forte com a moral e com a política, portanto, passível de disputas e contradições? Por que o "centro" não vai para a periferia, no sentido de entender que existem outras formas de manifestar o que seria próprio do sobralense?

Mesmo assim, deve-se pensar o centro, que corresponde ao sítio histórico tombado, como espaço da multiplicidade de atitudes, ações, reações e mediações. É um espaço que comporta o ruído da multidão também. O centro da cidade de Sobral é muito mais denso e complexo do que o exaltado nas fontes aqui selecionadas e discutidas, que tratam sobre o patrimônio histórico, assim como do PDDU ou o livro didático. Inclusive, boa parte das pessoas que compõem a confusão do dia são moradoras de outros bairros e têm outras histórias para contar, remetendo a tradições com perfis diferentes da gerada pela política pública oficializada pelo Estado. Além disso, é comum ouvir narrativas em que não se consideram o centro como se fosse um bairro. O termo "rua", constantemente utilizado para designar o centro, é significativo para demonstrar isso. As pessoas que vão para a "rua", somam-se aos moradores do centro, formando o turbulento barulho do grande aglomerado de pessoas que passam ou param. Além do termo "rua" que é mais comum, alguns dizem que vão para a "cidade". Isso denota uma conjugação de sentidos e denominações múltiplas ao espaço central da cidade, que vão além do entendimento como lugar que faz pensar a "sobralidade" e sua tradição. Pelo contrário, é arena pública que mistura práticas distintas por parte dos frequentadores e moradores do local, dando significados diferentes ao lugar.

A monumentalização, portanto, se mistura com outras dinâmicas e transformações que entram em tensão com a necessidade de preservação. $\mathrm{O}$ intérprete do espaço trabalha com possibilidades inúmeras de experiências sensoriais, e, todo tempo, vivencia distintos e complexos tipos de relações sociais no meio urbano que se modificam constantemente. Isto impossibilita uma rija base conceitual que possa ser tida como definitiva no pensamento sobre uma unidade cultural que justifique a preservação de um patrimônio cultural, que identifique a "todos" e crie uma homogeneidade. O desafio da interpretação está em conviver com o imponderável, com a insegurança e com a incerteza das relações mutantes da cidade que, no caso de Sobral, pode variar, desde um movimento intenso com fortes marcas de impessoalidade, até movimentos rotineiros e acolhedores de pessoas que passam e são reconhecidas, sentam-se e conversam, mostrando outras histórias e tradições. Muitas histórias surgem nestes diferentes ambientes e movimentos. Esta dificuldade do pesquisador de dar conta de uma totalidade das práticas cotidianas e tradições presentes no espaço urbano, para criar uma unidade cultural, o obriga a fazer seleções de alguns aspectos. A seleção é sempre arbitrária e tem relação com interesses políticos e morais que se misturam com a perspectiva ética, metodológica e teórica do analista.

Por sua vez, a gestão do município precisa desta unidade arbitrária que fala de uma identidade cultural, como homogênea, para acionar, com melhor eficácia, suas intervenções na cidade e disciplinar as condutas dos moradores, tanto no que se refere à materialidade do uso do espaço, quanto na sua produção simbólica. Isso promove capital político, se for eficaz e se conseguir adesão dos eleitores, se o poder público encontrar nesta unidade uma justificativa para fazer de uma forma que possa ser sustentada na ideia de que esta maneira escolhida seja considerada verdadeira ou única possível. Todas as demais que seriam diferentes, nesta perspectiva, seriam entendidas como moralmente incorretas, negligentes e inconsequentes. Para isso, investir em políticas patrimoniais não é suficiente. As demais políticas públicas devem estar articuladas nesta investida, como a de educação e urbanização, por exemplo. 
O poder público tem dificuldades em lidar com práticas cotidianas que não são estáveis, apesar de se apresentarem como rotineiras, já que precisa ter controle e disciplina dos movimentos. Como lembra Freitas (2005), as pessoas são agentes sociais que estão, criativamente e cotidianamente, construindo novas práticas, assim como revendo atitudes e comportamentos que, com o tempo, podem ser vistas como rotineiras. $\mathrm{O}$ contexto de situação e o agente que classifica a prática é que vai qualificá-la como rotina, tradição ou inovação, de acordo com seus códigos de avaliação. O movimento e ocupação do centro de Sobral é um exemplo dessa dificuldade de interpretação, por resguardar experiências sociais e práticas bastante diferentes, não permitindo qualificações fixas, como muitas vezes a política de preservação do patrimônio leva a crer. O corpo individual, seu movimento e criatividade é que promovem esta dificuldade. Para estes corpos, o centro, ao contrário das narrativas que falam da monumentalização, que tendem a estabilizar uma imagem referencial, é extremamente plural, complexo e mutante no que se refere às práticas cotidianas dos seus agentes, portanto, também complexo em suas tradições e histórias ${ }^{x x i x}$.

O centro tem uma forte ligação com a periferia no que se refere à história contada para justificar a monumentalização - ligação não lembrada por esta política específica -. Esta relação entre periferia e política de preservação cultural foi tema, e continuará sendo, de outros textos do articulista. Resta-nos continuar a seguir esta pluralidade ilimitada de possibilidades de identificação cultural coletiva e apontar algumas reflexões importantes a serem consideradas para melhor pensar as políticas de preservação do patrimônio cultural ${ }^{\mathrm{xxx}}$.

\section{Referências bibliográficas}

Balandier, G. (1997). A desordem: elogio do movimento. Rio de Janeiro: Bertrand Brasil.

Barbosa, M. E. J., Lucas, M. R. L., Souza, R. N. R., \& Vasconcelos, R. I. V. (2000). Sobral: Patrimônio Histórico. Sobral: Prefeitura Municipal de Sobral.

Caracristi, I., \& Saboya, G. (2002). Descobrindo e construindo Sobral: conbecimentos de Geografia e História. Fortaleza: Edições Demócrito Rocha.

Deleuze, G. (1997). Mil platôs: capitalismo e esquizofrenia. São Paulo: Editora 34.
Duarte Júnior, R. (2012). Sítios Históricos Brasileiros: monumento, documento, empreendimento $e$ instrumento - o caso de Sobral-CE. (Tese de Doutorado em Arquitetura e Urbanismo). Faculdade de Arquitetura e Urbanismo da Universidade de São Paulo, São Paulo.

Freitas, N. A. (2000). Sobral, opulência e tradição. Sobral, CE: Edições UVA.

Freitas, N. A. (2003). Práticas, rituais e regras de disputa no tempo da política em Sobral. In R. V. A. Carvalho (Org.). A produção da política em campanhas eleitorais: eleições municipais de 2000 (pp. 211-230). Campinas, SP: Pontes.

Freitas, N. A. (2005). O sabor de uma cidade: práticas cotidianas dos habitantes de Sobral. (Tese de Doutorado em Sociologia). Universidade Federal do Ceará, Fortaleza.

Freitas, N. A. (2010). Ação, efeito e manobras: o "artefato primoroso" da monumentalização de Sobral e seus usos no campo político. In N. A. Freitas, V. C. C. Holanda \& M. Maria Júnior (Orgs.). Múltiplos olhares sobre a cidade e o urbano: Sobral e região em foco (pp. 216-243). Sobral, CE: UECE/UVA.

Frota, D. J. T. (1995). História de Sobral. Fortaleza: Imprensa Oficial do Ceará.

Henriques, E. B. (2004). O Patrimônio nas Políticas Territoriais. In Actas do $V$ Congresso de Geografia Português (pp. 1-11). Portugal. Recuperado em 29 julho, 2019, de

http://www.apgeo.pt/files/docs/CD V Congresso APG/web/ pdf/E5 14Out Eduardo $\% 20$ Brito $\% 20$ Henriques.pdf

Herzfeld, M. (1991). A place in history: social and monumental time in a Creta town. Princeton: Pinceton University Press.

Le Goff, J. (1994). Documento/monumento. In J. Le Goff. (Org.). História e memória (pp. 535549). Campinas, SP: Editora da UNICAMP.

Mayer, A. (1987). A importância dos "quasegrupos" no estudo das sociedades complexas. In B. Feldman-Bianco (Org.). Antropologia das sociedades contemporâneas (pp. 127-158). São Paulo: Global.

Mont'Alverne Girão, G. G., \& Soares, M. N. M. (1997). Sobral: história e vida. Sobral, CE: Edições UVA.

Palmeira, M., \& Heredia, B. (1995). Os comícios e a política de facção. Anuário Antropológico, 19 (1), 95-125. Recuperado em 29 julho, 2019, de https://periodicos.unb.br/index.php/anua rioantropologico/article/view/6587. 
Silva, E. P. (2000). Patrimônio e identidade: desafios do turismo cultural. ANTROPOlógicas, (4), 217-224. Recuperado em 29 julho, 2019, de https://revistas.rcaap.pt/antropologicas/a rticle/view/932.

Silva Júnior, A. S. (2015). Cidades Sagradas: da Roma Cearense à "Jerusalém Sertaneja" - A igreja Católica e o desenvolvimento urbano no Ceará (1870-1920) - Sobral e Juazeiro do Norte. $1^{\text {a }}$. ed. Sobral, CE: ECOA.

\section{Notas}

i Este artigo é uma revisão e atualização de capítulo de tese de doutorado do articulista defendida em 2005, no programa de Pós-graduação em Sociologia da Universidade Federal do Ceará, que teve como título "O sabor de uma cidade: práticas cotidianas dos habitantes da cidade de Sobral".

ii Segundo o IBGE, Sobral tem uma população estimada em 2018 de 206.664 mil habitantes, com taxa de urbanização de 88,35\% e IDHM (2010) de 0,714 , ficando acima da média do estado de 0,682 e próximo do nacional de 0,727 (fonte: Atlas do Desenvolvimento Humano na página: http://www.atlasbrasil.org.br/2013/pt/perfil_m/s obral ce).

iii A discussão aqui proposta faz parte de pesquisa mais ampla, que envolve inúmeras outras fontes e outras questões sobre o tema, iniciada em 1997, quando o articulista entra como aluno no mestrado em sociologia, na Universidade Federal do Ceará, passando pelo doutorado na mesma IES e área, finalizado em 2005, e pelo pós-doutorado em Estudos Culturais na Universidade Federal do Rio de Janeiro que terminou em 2011. É um projeto que está presente até os tempos atuais, 2019, nas atividades vinculadas ao Laboratório das Memórias e das Práticas Cotidianas - LABOME, da Universidade Estadual Vale do Acaraú - UVA, IES localizada na já citada cidade de Sobral. O objetivo geral do projeto é organizar banco de dados documentais com documentos especiais (imagem e áudio), que possa servir como fonte primária para compreender a história e as diferentes formas de ocupação do espaço urbano de Sobral. A relação com o patrimônio histórico aparece ampliando o conceito, entendendo que este patrimônio não se restringe ao que está situado no sítio histórico tombado pelo IPHAN, incluindo outras regiões da cidade, especialmente a periferia. iv Um exemplo foi matéria do Jornal Diário do Nordeste de 9 de agosto de 1997 que tinha como título "Corredor cultural preserva a sobralidade triunfante". O título se refere a uma rua onde estão o Teatro São João, o Museu Dom José (na época o quinto em arte sacra do Brasil, no que se refere a quantidade de itens do acervo), a Praça São João que, em sua esquina está localizado a Igreja do Menino Deus. Ainda na Rua Dom José, encontrase também a Escola de Música de Sobral, abrigada em um antigo casarão do século XIX, e a Casa de Cultura, espaço de exposições e que tem um cinema. A Casa de Cultura, durante muito tempo, também abrigou a Secretaria de Cultura do município.

v Sobre isso, Freitas (2000).

vi A chapa Cid Gomes e Edilson Aragão (PSDB / PT / PSB / PCdoB / PTB) ganhou com 63,97\% dos votos, contra Cândida Figueiredo e Padre Zé Linhares (PDT / PPB / PMDB), com 25,65\% dos votos e Marco Prado e José Prado (PFL / PL), com $10,39 \%$ dos votos. Esta informação pode ser vista no sistema:

http://www.tse.jus.br/eleicoes/eleicoesanteriores/eleicoes-1996/resultados-das-eleicoes.

vii Sobre o detalhamento e discussão sobre o "tempo da política" em Sobral nas eleições de 1996 e 200, Freitas (2003).

viii Acontece que este grupo também é tradicional na cidade. O pai do Candidato, por exemplo, José Euclides Ferreira Gomes, foi prefeito de Sobral em 1977. O primeiro prefeito da cidade Vicente Cesar Ferreira Gomes, em 1890, foi da família. Antes da campanha, eram aliados dos "Prados" e Cid Gomes já havia perdido uma eleição como candidato a vice do José Linhares Pontes em 1988, conhecido como Padré Zé, que era aliado dos "Prados". Sobre isso, Mont'Alverne Girão e Soares (1997). Sobre a discussão relacionada à cultura política em Sobral, Freitas (2003).

ix A Casa de Cultura foi reconstruída para abrigar um cinema, um pequeno espaço com palco de teatro e local de exposições artísticas. Nas gestões entre 1997 e 2016 foi sede da Secretaria de governo responsável pela gestão das políticas culturais e do turismo.

x Sobre o detalhamento e discussão sobre o processo de monumentalização da cidade a partir do processo de instrução enviado ao IPHAN, Freitas (2010).

xi O documentário "Para sempre Sobral" de 
Moisés Magalhães, encomendado pela Prefeitura de Sobral e lançado no dia 10 de março de 2005, é um exemplo deste tipo de narrativa triunfalista que exalta o caráter especial de Sobral relacionado ao "moderno". Recuperado de https://www.youtube.com/watch?v=Ruj2TbhuDI Q

xii Exemplo desta tensão e pressão social para implementação de reformas em edificações no sítio histórico pode ser visto na seguinte matéria jornalística:

http://blogs.diariodonordeste.com.br/zonanorte/s obral/14016/14016. Duarte Júnior (2012), também chama atenção de alguns exemplos da mesma natureza.

xiii Aqui entende-se como quase-grupo, no sentido definido por Mayer (1987). O autor americano define este conceito como diferente ao de grupo. Neste último existe uma interação entre seus membros e não necessariamente precisa de um "chefe" como referência central e integradora. A institucionalização do grupo e a sua liderança muda de tempos em tempos, sem prejuízo para a instituição, com estatuto e regras definidas. O grupo teria maior uniformidade e continuidade, e a chefia não é vitalícia. Já o quase grupo, pelo contrário, depende de um indivíduo como foco mobilizador central. Em geral, as ações individuais dos que aderem ao quase-grupo, só são valorizadas quando direcionadas a um chefe central. O crédito das ações com outros membros do quase grupo é minimizado. Como lembra Mayer (1987), a interação é formada por um conjunto de ações inseridas em conexões sociais pertencentes a campos de sociabilidade distintos, formando redes segmentares e provisórias, aderindo a um nome central, uma pessoa. É comum em Sobral, o quasegrupo ser identificado por um nome de família. É o caso dos "Ferreiras Gomes", quase-grupo a qual os irmãos Cid, Ivo e Ciro Gomes fazem parte, além de Leônidas Cristino (eleito pelo PPS no mandato entre 2005/2008 e pelo PSB no mandato entre 2009/2013) e Clodoveu Arruda (eleito pelo PT no mandato entre 2013/2016, entendido como componente do quase-grupo), prefeitos que sucederam Cid Gomes. Em 2017, foi eleito Ivo Gomes, irmão de Cid, como prefeito.

xiv $O$ Estatuto das cidades (baseado nos dispositivos constitucionais Dispositivos Constitucionais: Lei no 10.257, de 10 de julho de 2001, e Vetos Presidenciais Lei no 6.766, de 19 de dezembro de 1979, Lei no 8.245, de 18 de outubro de 1991, Decreto no 5.790/2006, artigo 40, parágrafo terceiro) diz que o PDDU deve ser revisto depois de dez anos. Portanto, a gestão municipal antecipou-se ao prazo exigido.

$\mathrm{xv}$ Estas mesmas observações podem ser vistas em Freitas (2005).

xvi Sobre mais detalhes relacionados a influência da Igreja na evolução do espaço urbano em cidades pequenas e médias do interior do Ceará, Silva Júnior (2015).

xvii Esta nomeação é comum na capital cearense, Fortaleza, quando, em rodas de conversa, se lembra de Sobral. Até mesmo a imprensa nacional, em alguns momentos, chega a usar esta imagem para chamar a atenção de seus leitores. No dia da posse do presidente norte americano Donald Trump, saiu a seguinte notícia no portal da Globo: "No dia da posse de Trump nos EUA, a cidade de Sobral, no Ceará, conheceu o Bode Trump", publicado no endereço: https://extra.globo.com/noticias/brasil/no-diada-posse-de-trump-nos-eua-cidade-de-sobral-noceara-conheceu-bode-trump-20807733.html.

xviii Esta informação sobre o campus da UFC, não está contida no livro, já que aconteceu depois de sua edição e publicação.

xix As referidas peças podem ser vistas no site: http://museudomjose.com.br/wps/sala-dasliteiras/.

xx Segundo o que informa Mont'Alverne Girão e Soares (1997), o prédio onde está instalado o Museu foi construído em 1844, pelo primeiro Juiz de Paz de Sobral, Major João Pedro da Cunha Bandeira de Melo. Em 1933 foi comprado pelo Bispo Dom José, para abrigar o Palácio Episcopal até o seu falecimento em 1959. Já em 1951 funcionava como Museu Diocesano e só em 1971 foi inaugurado como Museu Dom José. Na década de 1980 ele passa a ser dirigido pela UVA. Em 1992 suspende suas atividades por conta da precariedade das instalações da edificação, e em 1997 é reaberto após reforma.

xxi Sobre isso, Frota (1995).

xxii $\mathrm{Na}$ estrada que sobe a Serra da Meruóca, próxima a Sobral, existe um santuário que lembra a história da escrava Romana que viveu, no final do século XIX, e sofreu torturas por parte de seu dono quando se negou a ter relações sexuais com ele. Morreu com cerca de 20 anos de idade. Saindo do santuário, inaugurado em 2002, tem um escadaria com cerca de 365 degraus que leva ao local onde está uma cruz lembrando o local de sua 
morte. Durante o percurso, tem passagens da via sacra de Jesus. Atribui-se milagres a santa popular. Fonte: Diário do Nordeste, acessado pelo link: https://diariodonordeste.verdesmares.com.br/sant uario-da-romana-inspira-devocao-e-fe-catolica1.2075921 , acessado em 30 de setembro de 2019.

xxiii Abolicionista que em 1883, fundou em Fortaleza, a Sociedade das Senhoras Libertadoras do Ceará. Ela é neta de José Xerez, primeiro intendente de Sobral, no Brasil colonial.

xxiv A reflexão sobre a força política de Dom José em Sobral, foi melhor discutida em outras obras do articulista. Sobre isso, Freitas (2000).

xxv O jornal norte-americano anuncia a demasiada ansiedade dos homens da ciência pela descoberta da curvatura da luz. Há também no museu a reprodução de um artigo de C. Davidson na revista inglesa Conquest referindo-se com detalhes à visita feita a Sobral.

xxvi O Becco do Cotovelo em Sobral é uma rua que só permite o trânsito de pedestres, no centro da cidade. É cultuado pelos seus frequentadores como coração de Sobral. Algumas narrativas contam que, não passar no Becco, é como se não tivesse ido a Sobral. A grafia repetindo a letra "c" duas vezes, tem relação com uma necessidade dos frequentadores de criarem uma noção de que é um espaço antigo e tradicional na cidade, lembrando de uma época em que a palavra se escrevia desta forma. O "Cotovelo" se refere ao formato da rua que tem uma curva, lembrando ao cotovelo de um braço levemente dobrado. Sobre isso, Freitas (2000).

xxvii Informações sobre o evento podem ser encontradas no site: http://www.facebook.com/CentenariodoEclipsed eSobral.

xxviii Exemplo do que se fala aqui pode ser visto na seguinte matéria publicada pelo jornal de circulação estadual, Diário do Nordeste, em 22 de outubro de 2009:

https://diariodonordeste.verdesmares.com.br/edit orias/regiao/demolicao-de-predio-historico-causarevolta-1.515091.

xxix Sobre isso, Freitas (2010).

xxx Algumas imagens e mapas relacionados a este artigo podem ser vistas no link: https://www.flipsnack.com/nilsonalmino/sobral.h tml. No mesmo sítio, tem outro link que leva ao filme "Sobral no Plural", produzido para pensar a cidade como dinâmica, diversa e múltipla, enriquecendo a narrativa oficializada pela política de preservação do patrimônio histórico. 